analysis of the full sample will seem to reveal a changing slope with increasing age-that is, a nonlinear age association. Here an interaction masquerades as a nonlinearity. Alternatively, if the true association with age is nonlinear, but the same among men and women, an analysis with a linear age term and an interaction by sex will likely find a significant interaction. This has led many to believe nonlinear modelling is a bridge too far. However, the problem in the above example is that the exposure (age) is associated with the effect modifier (sex). In the paper of Castaldi et $a l^{2}$ they have been careful to examine whether smoking was associated with the genotype they studied as a modifier, and report no association. And for gene-environment interactions this is less likely than for other modifiers. Moreover, there are ways to deal with the association. In the above example, for instance, one could test whether the association with age was not linear within sex.

In modern statistical software, testing for nonlinearity, and fitting dose-response models that do not assume constant slopes is straightforward. It is time to stop making a default assumption that continuous predictors have linear associations with health outcomes.

Competing interests None.
Provenance and peer review Commissioned; not externally peer reviewed.

Accepted 20 December 2010

Published Online First 26 May 2011

Thorax 2011;66:841-842.

doi:10.1136/thx.2010.154195

\section{REFERENCES}

1. Pope CA3rd, Burnett RT, Krewski D, et al. Cardiovascular mortality and exposure to airborne fine particulate matter and cigarette smoke: shape of the exposure-response relationship. Circulation 2009; 120:941-8

2. Castaldi PJ, Demeo DL, Hersh CP, et al. Impact of non-linear smoking effects on the identification of gene-by-smoking interactions in COPD genetics studies. Thorax 2011;66:903-9.

\title{
Preventing adolescents' uptake of smoking
}

\section{Tim Coleman, ${ }^{1}$ Linda Bauld ${ }^{2}$}

Smoking is the principal preventable cause of ill health worldwide. ${ }^{1}$ It not only affects smokers themselves but is also extremely harmful to non-smokers who inhale environmental tobacco smoke (ETS). ${ }^{2}$ In non-smoking adults, ETS exposure causes lung and other cancers, ischaemic heart disease, stroke, chronic obstructive pulmonary disease, asthma and other respiratory illnesses. ${ }^{3}$ Perhaps less well known by the general public is the threat that ETS inhalation poses for infants and children; there are strong associations with children's asthma, lower respiratory tract infection, sudden infant death syndrome, middle ear infection and bacterial meningitis. ${ }^{3}{ }^{4}$ Knowledge of the health risks of ETS exposure have led many countries, including the UK, to introduce laws that prohibit smoking in indoor public spaces like bars and pubs (smoke-free legislation). ${ }^{5}$ Advocates of smoke-free laws successfully argued for these on the basis of protecting non-

\footnotetext{
${ }^{1}$ Division of Primary Care, UK Centre for Tobacco Control Studies, University of Nottingham Medical School, Queen's Medical Centre, Nottingham, UK; ${ }^{2}$ Stirling Management School, UK Centre for Tobacco Control Studies, University of Stirling, Stirling, UK

Correspondence to Tim Coleman, University of Nottingham, School of Community Health Sciences, University Hospital, Nottingham NG7 2UH, UK; tim.coleman@nottingham.ac.uk
}

smokers who might work in or visit smoky environments. Consequently, as tobacco smoke has been completely eliminated from most situations in which adult non-smokers might encounter it, they are well protected from ETS. No similar protection exists for the children of smokers. Most of children's exposure to tobacco smoke occurs domestically ${ }^{3}$ but, internationally, there are no smoke-free laws which forbid smokers from 'lighting up' in their homes when children are present. Children's domestic ETS exposure therefore remains an important public health concern which, as Leonardi-Bee and colleagues ${ }^{6}$ show in this issue of Thorax, is even more harmful than was previously thought. The authors show that children's exposure to ETS from parental smoking has a pervasive inter-generational behaviour-modelling effect such that the children of smokers are much more likely to become smokers themselves. Their systematic review and meta-analysis collated findings from 58 epidemiological studies investigating associations between parental smoking and the subsequent development of established smoking in offspring. When both parents smoke, the risk of their children becoming smokers almost triples; if only one parent or a sibling smokes the risk is lower but, even then, children are between 1.75 times and twice as likely to become smokers than those not exposed to parents' or siblings' smoking. The consistency of findings from individual studies comprising the review is striking; virtually all component studies reported a positive association between parental/sibling smoking and children's subsequent uptake of the habit, lending strong support to the authors' conclusion that associations are probably causal. Of course, smoking is strongly associated with household psychosocial problems ${ }^{7} 8$ and it is possible that, for some young people, these issues have more of an impact on their future smoking behaviour than parental smoking itself. Nevertheless, it seems very unlikely that the normalising impact of persistent parental smoking within the home would have no effect. Parental smoking in the home therefore has direct, substantial and immediate impacts on children's health from inhaled ETS and also, in those children who become adult smokers as a consequence of learned smoking behaviour, it has serious longer-term indirect effects mediated by their future smoking. Leonardi-Bee and colleagues call for 'radical changes in public policy and behaviour and in the acceptability of smoking in places where children are present'. However, while arguments for eliminating smoking in the presence of children are compelling, quite how this could be achieved remains unclear.

Legislative changes that curtail widespread behaviours need both robust public support (to ensure that new laws are obeyed) and effective compliance mechanisms (to ensure that breaking new laws has a reasonable chance of incurring penalties). There was strong public support for smoke-free laws before these were introduced in the UK and public 
support increased after the introduction of the legislation, even among smokers. ${ }^{9}$ Observance of the smoke-free laws was rigorously enforced by local authority environmental health departments. These factors probably explain why in Scotland smoke-free legislation has been thoroughly implemented with high compliance, ${ }^{10}$ and in England it is now highly unusual to inhale other people's tobacco smoke in indoor public spaces. ${ }^{11}$ Not all public health-orientated legislation is adhered to as comprehensively-for example, using a mobile telephone while driving is also illegal in the UK but car drivers are often seen talking on their telephones.

A radical change in public health policy might be to ban smoking in public outdoor places where children are present (eg, children's play areas or in all school grounds). Such a law has recently been introduced in Spain and its impacts need evaluating. ${ }^{12}$ However, many Spanish smokers will still probably smoke in the home, 'teaching' their children to smoke and exposing them to ETS. Indeed, it is difficult to envisage how public healthorientated legislative changes could influence parents' smoking behaviour to such an extent that their children would never see them smoking. Laws banning smoking in homes where children live would be unlikely to have much effect; many smokers at whom such laws would be targeted would probably oppose them and there would be no clear mechanism for enforcing compliance. If people choose to ignore the law and smoke in their homes, how and by whom would this be detected? For law breakers, would there be any significant risk of sanction? If legislation is unlikely to stop children from seeing their parents smoke or inhaling ETS from their cigarettes, then what other measures could achieve this? Ideally, any smokers who become parents would immediately stop smoking, transforming themselves into positive health role models for their children. Some parents do manage this but many do not-illustrated, for example, by the very high rates of relapse to smoking after childbirth observed among women who managed to stop smoking while pregnant. ${ }^{13}$ It is therefore clear that a proportion of parents will continue to smoke in their homes when children are present; finding and implementing strategies for minimising the impacts of this destructive behaviour should be a public health priority.

Completely preventing children from observing parental smoking is likely to be an elusive goal, but smoking uptake can be prevented in other ways such as restricting young people's access to cigarettes. ${ }^{14} 15$ Reviews have shown that legislative restrictions on the purchase of cigarettes by young people are effective when concurrent measures are taken to ensure that retailers obey such laws. ${ }^{14} 15$ Previous studies have generally investigated the impact of restrictions on the purchase of cigarettes by young persons and not on their smoking behaviour; the few studies that have looked for a link between purchase restrictions and smoking prevalence have found none. ${ }^{14}$ However, Millett and colleagues use robust national survey data to demonstrate that increasing the legal purchase age of cigarettes in the UK (from 16 to 18 years) caused concurrent reductions in smoking by English children aged 11-15 years. ${ }^{16}$ Purchase restrictions were introduced at a time when the prevalence of smoking among teenagers was already falling, so the authors used multivariate analyses to investigate the impact of the new law and other factors on smoking prevalence in the years before and immediately after the new restrictions were introduced. They found that the prevalence of smoking fell more than expected after cigarette purchase restrictions were introduced, even after taking into account other factors and the underlying downward trend in smoking behaviour over time.

The oldest children surveyed were only 15 years old and, as fewer 15-year olds than 16-17-year olds regularly smoke, one would expect the impact of purchase restrictions to be less in the survey sample than in all young smokers affected by legislation. The authors postulated that young people from economically disadvantaged backgrounds might find it easier to circumvent the new restrictions by obtaining cigarettes from family, friends and other non-retail sources, but this did not happen. Young smokers who received free school meals (a proxy for lower socioeconomic status) were no more likely to buy cigarettes from sources other than shops. The legislation therefore not only contributed to lower smoking by 11-15-year olds but it affected students from different socioeconomic groups equally.

Preventing smoking uptake by young people is essential to ensure that falls in smoking prevalence are sustained in the longer term; uptake must be low to guarantee that, at a population level, older 'quitters' are not simply replaced by similar numbers of younger people starting to smoke. However, the evidence base for prevention is relatively weak compared with that for cessation ${ }^{17}{ }^{18}$; in the UK there is no coherent national strategy for smoking prevention but costeffective cessation interventions ${ }^{19-21}$ are routinely used in clinical practice. It now seems likely that effectively restricting young people's access to cigarettes reduces their propensity to smoke; however, we also now know that smoking behaviour is vertically transmitted between generations. Preventive interventions aimed at young people, although important, may be too late for some. Approaches towards preventing smoking uptake by young people need to begin before birth and should engage anyone who is actively considering becoming a parent as well as those who already have children.

\section{Competing interests None.}

Provenance and peer review Commissioned; not externally peer reviewed.

Published Online First 17 April 2011

Thorax 2011;66:842-844.

doi:10.1136/thx.2011.161042

\section{REFERENCES}

1. World Health Organization. The World Health Report 2002: Reducing Risks, Promoting Healthy Life. Geneva: World Health Organization, 2002.

2. IARC Monographs on the Evaluation of Carcinogenic Risks to Humans. Vol. 83: Tobacco Smoke.

3. Tobacco Advisory Group of the Royal College of Physicians. Going Smoke-free: The Case for Clean Air in the Home, At Work and in Public Places. London: Royal College of Physicians of London, 2005.

4. Tobacco Advisory Group of the Royal College of Physicians. Passive Smoking and Children. London: Royal College of Physicians, 2010.

5. Hopkins DP, Razi S, Leeks KD, et al. Smokefree policies to reduce tobacco use. A systematic review. Am J Prev Med 2010;38(2 Suppl):S275-89.

6. Leonardi-Bee J, Jere ML, Britton J. Exposure to parental and sibling smoking and the risk of smoking uptake in childhood and adolescence: a systematic review and meta-analysis. Thorax 2011;66:847-55.

7. Pickett KE, Wilkinson RG, Wakschlag LS. The psychosocial context of pregnancy smoking and quitting in the Millennium Cohort Study. J Epidemiol Community Health 2009;63:474-80.

8. Lloyd-Richardson EE, Papandonatos G, Kazura A, et al. Differentiating stages of smoking intensity among adolescents: stage-specific psychological and social influences. J Consult Clin Psychol 2002;70:998-1009.

9. Department of Health. Smokefree England-One Year On. London: Department of Health, 2008.

10. Hyland A, Hassan LM, Higbee C, et al. The impact of smokefree legislation in Scotland: results from the Scottish ITC: Scotland/UK longitudinal surveys. Eur J Public Health 2009;19:198-205.

11. Hargreaves $\mathbf{K}$, Amos A, Highet $G$, et al. The social context of change in tobacco consumption following the introduction of 'smokefree' England legislation: a qualitative, longitudinal study. Soc Sci Med 2010;71:459-66. 
12. Rada AG. Spain's tougher line on smoking in public places spreads to other countries. BMJ 2011;342:d617.

13. Hajek $\mathbf{P}$, Stead LF, West R, et al. Relapse prevention interventions for smoking cessation. Cochrane Database Syst Rev 2005;(1):CD003999.

14. Richardson L, Hemsing N, Greaves L, et al. Preventing smoking in young people: a systematic review of the impact of access interventions. Int $J$ Environ Res Public Health 2009;6:1485-514.

15. Stead LF, Lancaster T. Interventions for preventing tobacco sales to minors. Cochrane Database Syst Rev 2005;(1):CD001497. [Update of Cochrane Database Syst Rev 2002;(1):CD001497]
16. Millett C, Lee J, Gibbins D, et al. Increasing the age for the legal purchase of tobacco in England: impacts on socioeconomic disparities in youth smoking. Thorax 2011;66:862-5

17. Sowden A, Arblaster L, Stead L. Community interventions for preventing smoking in young people. Cochrane Database Syst Rev 2003;(1):CD001291. [Update of Cochrane Database Syst Rev 2000;(2): CD001291].

18. Brinn MP, Carson KV, Esterman AJ, et al. Mass media interventions for preventing smoking in young people. Cochrane Database Syst Rev 2010;(11):
CD001006. [Update of Cochrane Database Syst Rev 2000:(2):CD001006]

19. Hughes JR, Stead LF, Lancaster $T$, et al. Antidepressants for smoking cessation. Cochrane Database Syst Rev 2007;(1):CD000031. [Update of Cochrane Database Syst Rev 2004;(4): CD000031].

20. Stead LF, Perera R, Bullen C, et al. Nicotine replacement therapy for smoking cessation. Cochrane Database Syst Rev 2008;(1):CD000146.

21. Cahill K, Stead LF, Lancaster T, et al. Nicotine receptor partial agonists for smoking cessation. Cochrane Database Syst Rev 2007;(1):CD006103.

\section{Protecting young people from smoking imagery in films: whose responsibility?}

\section{$\checkmark$ Ailsa Lyons, John Britton \\ EDITOR'S \\ CHOICE}

Every day thousands of children try a cigarette for the first time, a seemingly innocuous step that for many leads to a lifelong and ultimately fatal addiction to smoking. Preventing this early experimentation is crucially important to preventing the huge toll of death and disability-particularly from respiratory diseases-that smoking causes. There is now increasing international evidence that exposure to smoking behaviour and other imagery in films is a major cause of smoking experimentation and uptake among children and young people. ${ }^{1-3}$ Three new studies in this issue of Thorax provide further evidence on this effect, this time in UK populations.

In a study of 15-year-old adolescents in the Avon birth cohort, Waylen et al demonstrate a direct relation between exposure to smoking in films and experimentation with smoking which remains significant even after exhaustive adjustment for potential confounders. Among Scottish adolescents exposed to smoking in films, Hunt et at ${ }^{5}$ report an exposurerelated increase in the odds of smoking that was enhanced by allowance for

UK Centre for Tobacco Control Studies, Division of Epidemiology and Public Health, The University of Nottingham, Nottingham, UK

Correspondence to Ailsa Lyons, UK Centre for Tobacco Control Studies, Division of Epidemiology and Public Health, The University of Nottingham, Clinical Sciences Building, City Hospital, Hucknall Road, Nottingham NG5 1PB, UK; mcxal4@nottingham.ac.uk 2002. repeated viewings. In a wider European study, Morgenstern et al demonstrate exposure-related increases in the odds of smoking among adolescents exposed to smoking in films in six countries, including the UK, demonstrating that this association applies across different cultural contexts and levels of implementation of other tobacco control policy. These new studies thus provide further and urgent evidence in support of calls-as yet unheeded-for a radical overhaul of film classification to protect all children and young people from this pervasive and highly damaging imagery. 2 3 $7-9$

The British Board of Film Classification (BBFC) is an independent organisation which, in return for fees paid by film makers, allocates all UK films intended for general release into one of five age classifications (table 1). ${ }^{10}$ The BBFC lists drug misuse and dangerous imitable behaviours as examples of harmful behaviour, and both $U$ and PG category guidance specifically proscribes 'potentially dangerous behaviour which young children are likely

to copy'. ${ }^{10}$ Smoking imagery is excluded from these categories, however, and acknowledged only, and if at all, in consumer advice printed on publicity materials and DVD cases or in extended classification information published on the BBFC website. ${ }^{11}$ As a result, as we have recently demonstrated, smoking and other forms of smoking imagery are extremely common in films classified as suitable for viewing by children and young people in the UK, and particularly so in films classified as suitable for viewing by children aged 12 and over. ${ }^{12}$

Our strong impression formed while carrying out that work is that, while some smoking in age-restricted films appears to be justified on artistic or factual grounds, the great majority is not. An example of the latter occurs in Avatar, the most popular film of all time and classified 12A in the UK, in which a lead adult character emerges from a sleeping pod in a science base on a distant planet over a century into the future to say, "Who's got my goddamn cigarette?" She then lights up and smokes throughout a conversation with other characters in a working environment in which smoking would be inconceivable even on 21st century Earth. The director of Avatar, James Cameron, justified the smoking on the grounds that 'from a character perspective, we were showing that Grace doesn't care about her human body, only her Avatar body'.13 Another and more egregious example is Remember Me, a 2010 'romantic drama set in New York City during the summer of

Table 1 British Board of Film Classification age-rated restriction categories for films viewed in UK cinema

\begin{tabular}{ll}
\hline Category & Description \\
\hline Universal (U) & Suitable for all audiences \\
Parent guidance (PG) & General viewing, but some scenes may be unsuitable for young children \\
$12 / 12 A^{*}$ & (12) Suitable for 12 years and older; (12A) under 12s must be accompanied by an adult \\
15 & Suitable for 15 years and over \\
18 & Suitable for 18 years and older
\end{tabular}

*12 and 12A rated films have been amalgamated since the $12 \mathrm{~A}$ film rating replaced the 12 rating for cinema film viewing in 